\title{
Iceland's doctors rebuffed in health data row
}

Alison Abbott

The Icelandic Medical Association (IMA) has failed to reach agreement with the genomics company deCODE Genetics over Iceland's new national health sector database, which is to be run by the company. The dispute centres over the plan for automatic inclusion of patients' health records in the anonymized database.

Opponents are concerned that deCODE, which launched itself on the Nasdaq stock exchange last month, is painting an excessively optimistic picture of the conflict to shareholders.

The new system will collect and store information from the Icelandic health service. Under the present rules, patients would be presumed to have given their consent to inclusion even if they had not been consulted.

The Icelandic government approved plans for the database in 1998. In January this year it granted deCODE a 12-year licence to operate the database and market - in encrypted form - the information it contains together with the company's own genomics data of the Icelandic population.

A law passed in 1998 requires health records to go into the database unless an individual actively opts out. But the IMA insists that transfer should be based on informed, rather than presumed, consent - the issue should be discussed with each patient.

Six months ago, the two sides embarked on discussions to resolve the issue. But compromise has proved impossible, and a joint press release was issued last week reporting that talks "had been concluded".

The IMA is upset that deCODE has issued an English translation of the press release - now posted on the Nasdaq website — giving a more positive slant to the discussions than the Icelandic original had. The Icelandic release, for example, says that the talks "covered the content and have been to the point", whereas deCODE's English version says the discussions "have been both positive and productive".

Sigurbjörn Sveinsson, chairman of the IMA, says that deCODE "did not seek our approval of their English version, and there is obvious inconsistency in the two versions".

But Kári Stefánsson, deCODE's chief executive officer, says the company does not need the IMA's approval to proceed with the database on the basis of presumed consent. "The law is quite clear," he says, adding that he is still keen to make peace with the IMA.

Most Icelandic doctors oppose presumed consent, and many say they will not hand over records that are not already in hospital

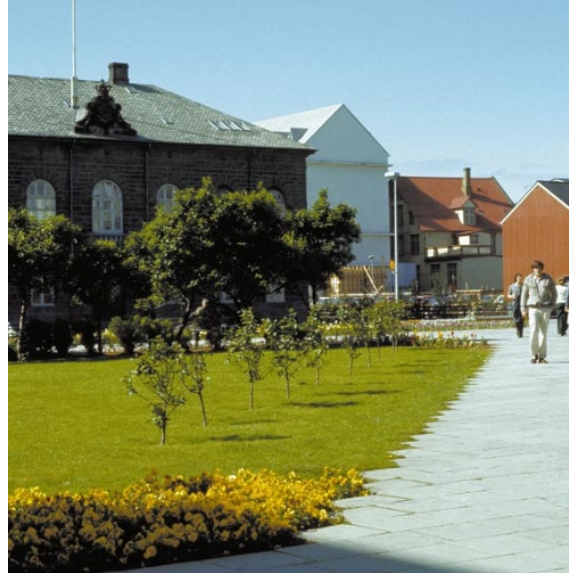

It's the law: Iceland's parliament (above) has approved 'presumed consent'.

databases. "I don't feel comfortable with handing over data when we don't know how it will be used in the future," says Sigurdur Björnsson, an oncologist on the IMA board.

Stefánsson says that only a few records remain outside public institutions, and the project does not require support from all the doctors, as the database does not need to represent $100 \%$ of the population to be useful. i http://www.decode.com

http://www.mannvernd.is/english/index.html

\section{Astronomers reveal the secrets of the name game}

\section{Steve Nadis}

Perhaps it was inevitable. Features on the surface of Eros, the near-Earth asteroid now being observed by the NEAR Shoemaker spacecraft, have officially been given the names of famous lovers in myth and literature, such as Orpheus and Eurydice, Don Juan, Cupid and Lolita.

Assigning such names is the job of the working group for planetary-system nomenclature of the International Astronomical Union (IAU), which convened this month in Manchester, England, at a meeting of the IAU general assembly. The names Bill and Monica are said to have been summarily rejected.

This year the working group has selected more than 200 names for the satellites of Uranus and for craters and other features seen on the Moon, planets and asteroids.

The system is intended to make life easier for researchers, rather than commemorate people, explains Brian Marsden, a member of the working group who is based at the Harvard-Smithsonian Center for Astrophysics in Cambridge, Massachusetts.

Yet commemoration plays an important role. A crater on the moon was named after

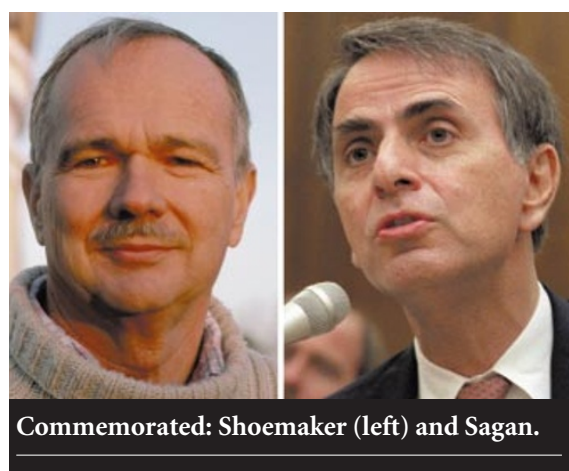

the planetary scientist Eugene Shoemaker, for example, and one on Mars was named after the astronomer Carl Sagan - both of whom became eligible, according to IAU rules, three years after their deaths.

But the desire to honour Shoemaker and Sagan could create problems, says Marsden. “There is a tradition that you don't use the same name for different astronomical bodies, but these names have been mentioned for other objects as well."

Another point of contention was raised by some of the younger astronomers, who complained that most members of the working group have held their posts since the 1970s. "There's a feeling that people should not do more than three [three-year] terms, so that others won't feel left out," says Marsden, who is starting his third term and is prepared to retire after the next IAU general assembly meeting in 2003.

One change introduced this year establishes an appeal process, allowing any IAU member to object to a new name within three years of its announcement. No such challenges have yet been raised, but a Japanese amateur astronomer did ask the working group to reconsider the name for an asteroid he discovered. His suggestion had been rejected because it was the name of the company he worked for, but the committee reversed its decision, and the name, Denso, was approved.

Most names are drawn from history and literature, rather than the corporate world. Names for the moons of Uranus - Caliban, Sycorax, Setebos, Stephano and Prospero were taken from Shakespeare's play The Tempest. The last three names replace the temporary designations S/1999U1, U2 and U3. "I'm perfectly happy to use numbers, which I find easier to remember," Marsden says. "But the public likes to have names." 